American Journal of Applied Sciences 6 (1): 137-142, 2009

ISSN 1546-9239

(C) 2009 Science Publications

\title{
Effects of Spot Diameter and Sheets Thickness on Fatigue Life of Spot Welded Structure based on FEA Approach
}

\author{
M.M. Rahman, A.B. Rosli, M.M. Noor, M.S.M. Sani and J.M. Julie \\ Automotive Excellence Center \\ Faculty of Mechanical Engineering \\ Universiti Malaysia Pahang \\ Locked Bag 12, 25000 Kuantan, Pahang, Malaysia
}

\begin{abstract}
This study presents the effect of the spot weld and sheets thickness on the fatigue life of the of the spot-weld joints to predict the lifetime and location of the weakest spot-welds due to the variable amplitude loading conditions. A simple model was used to illustrate the technique of spot-weld fatigue analysis. Finite element model and analysis were carried out utilizing the finite element analysis commercial codes. Linear elastic finite element analysis was carried out to predict the stress state along the weld direction. It can be seen from the results that the predicted life greatly influence the sheet thickness, nugget diameter and loading conditions of the model. Acquired results were shown the predicted life for the nugget and the two sheets around the circumference of the spot-weld at which angle the worst damage occurs. The spot-welding fatigue analysis techniques are awfully essential for automotive structure design.
\end{abstract}

Key words: Spot-weld structure, finite element analysis, fatigue-life, sheet thickness, spot diameter

\section{INTRODUCTION}

Spot welding is a widely employed technique to join sheet metals for body and cap structure in the automotive industry. The strength of the spot welds in the unibody vehicle structure determines the integrity of the structural performance during the vehicle operations. Most spot welds generally carry only shear forces but spot welds can also experience a significant amount of peel force or the force normal to the spot weld in certain loading conditions. The combination of the stress states and geometric shapes of the spot welds lead to stress concentration that can result in fatigue crack initiation around the spot weld. The presence of fatigue cracks can degrade structural performance and increase noise and vibration of the vehicle structure. Therefore, understanding of the fatigue strength for the spot welds is very important in automotive component design.

The static strengths of spot welds have also been investigated. Ewing et al. ${ }^{[1]}$ investigated the strength of spot welds in terms of the specimen geometry, welding parameter, welding schedule, base metal strength, testing speed and testing configuration. Zhang and Taylor $^{[2]}$ reported the thickness effect of spot welded structure on fatigue life. Pan and Sheppard ${ }^{[3]}$ calculated stress intensity factors for crack propagation through the thickness of plate by numerically utilizing finite element analysis. Lee et $a l^{[4]}$ adopted a fracture mechanics approach using the stress intensity factor to model their experimental results on the strength of spot welds in U-tension specimens under combined tension and shear loading conditions. Wung ${ }^{[5]}$ and Wung et al. ${ }^{[6]}$ obtained and analyzed test results from lap-shear, inplane rotation, coach-peel, normal separation and inplane shear tests and proposed a failure criterion based on the experimental data of spot welds in various specimens.

Some researchers ${ }^{[7-9]}$ have studied on the effects of base metal properties on the fatigue life of spot welds. They have also studied on the effects of loading conditions with different specimen types such as tensile shear, coach peel and cross tension specimens. These studied showed in general that fatigue life of spot welds depended on the loading conditions and base metal properties.

On the other hand, numerous researchers ${ }^{[1,10-14]}$ proposed analytical and/or empirical models to predict the fatigue strength of spot welds in the early vehicle design stage. Most of these models were developed based on the relationship between a fatigue damage parameter and number of cycles to failure of spot

Corresponding Author: M.M. Rahman, Faculty of Mechanical Engineering, Universiti Malaysia Pahang, P.O. Box 12, 25000 Kuantan, Pahang, Malaysia Tel: +6-09-5492207 Fax: +6-09-5492244 
welds. The objective of this study is to investigate the effect of the sheet thickness and diameter of the spot weld nugget on the fatigue.

\section{STRUCTURAL STRESS PARAMETER}

Welded joints experience highly localized heating and cooling from welding processes. As a result, the material properties around the welding joints can be significant variations after welding. The local geometry of the welded joints may have variations due to the amount of heat inputs and welding skills. These variations present significant difficulties for reliable fatigue prediction of welded joints.

Dong $^{[15-16]}$ proposed a structural stress parameter for welded joins based on local stresses at weld toe. A typical through-thickness stress distribution at a fatigue critical location and the corresponding structural stress definition for through-thickness fatigue crack at the edge of a spot weld are shown in Fig. 1 and 2. Stress distribution at the edge of the spot weld nugget is assumed as shown in Fig. 1. In Fig. 1, t represents the thickness of the sheet steel, $\sigma_{\mathrm{x}}$ and $\tau$ are the normal and transverse shear stress under axial force $\mathrm{P}$ respectively. The corresponding structural stress distribution is shown in Fig. 2. The structural stress $(\sigma)$ is expressed in Eq. 1:

$$
\sigma=\sigma_{\mathrm{m}}+\sigma_{\mathrm{b}}
$$

where, $\sigma_{\mathrm{m}}$ is the membrane stress component and $\sigma_{\mathrm{b}}$ is the bending stress component due to the axial force $\mathrm{P}$ in the $\mathrm{x}$ direction. The transverse shear stress can be calculated based on local structural shear stress distribution, however, the effect of transverse shear stress neglected since the spot weld does not experience significant transverse shear loads in general $^{[15]}$.

The structural stress is defined at a location of interest such as plane A-A in Fig. 3 and the second reference plane can be defined along plane B-B. Both local normal and shear stress along plane B-B can be obtained from the finite element analysis. The distance in local $\mathrm{X}$-direction between plane A-A and B-B is defined as $\delta$. The structural membrane stress and bending stress must satisfy Eq. 2 and 3 for equilibrium conditions between plane A-A and B-B. Equation 2 shows the force balances in $\mathrm{X}$-direction, evaluated along the plane B-B. On the other hand, Eq. 3 shows moment balances with respect to plane $\mathrm{A}-\mathrm{A}$ at $\mathrm{y}=0$. When $\delta$ between planes A-A and B-B becomes smaller then transverse stress $\tau$ in Eq. (3) is negligible. Therefore, Eq. 2 and 3 can be evaluated at Plane A-A in Fig. 3.

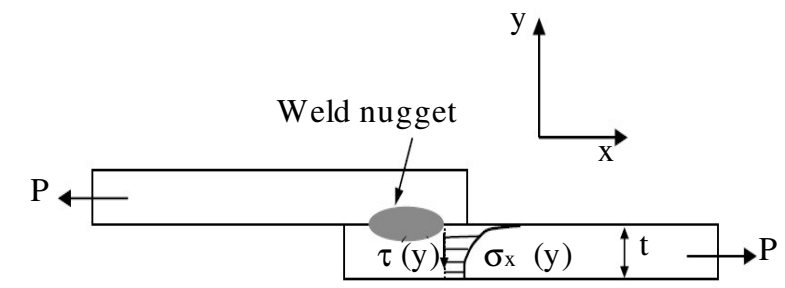

Fig. 1: Local normal and shear stress in thickness direction at the edge of a spot weld

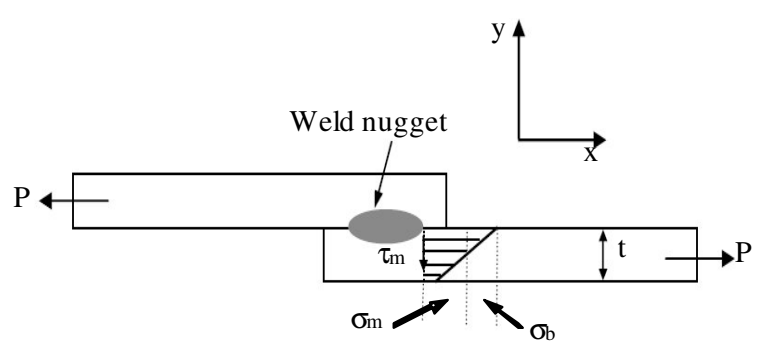

Fig. 2: Structural stress definition at the edge of spot weld nugget

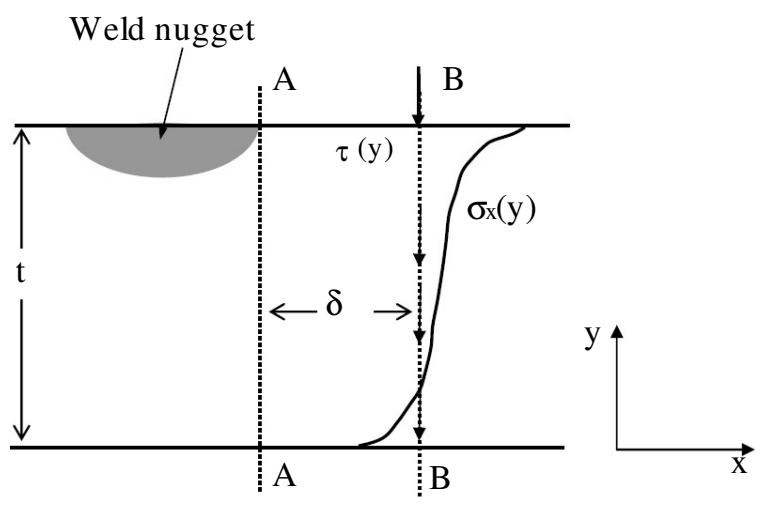

Fig. 3: Structural stress calculation procedure for fatigue crack in thickness direction at the edge of the weld nugget

$$
\begin{gathered}
\sigma_{\mathrm{m}}=\frac{1}{\mathrm{t}} \int_{0}^{1} \sigma_{\mathrm{x}}(\mathrm{y}) \mathrm{dy} \\
\sigma_{\mathrm{m}}\left(\frac{\mathrm{t}^{2}}{2}\right)+\sigma_{\mathrm{b}}\left(\frac{\mathrm{t}^{2}}{2}\right)=\int_{0}^{\mathrm{t}} \mathrm{y} \sigma_{\mathrm{x}}(\mathrm{y}) \mathrm{dy}+\delta \int_{0}^{\mathrm{t}} \tau(\mathrm{y}) \mathrm{dy}
\end{gathered}
$$

\section{DEVELOPMENT OF FEM}

Traditionally, a very detailed finite element model of a spot welded joint is required to calculate the stress states near the joint ${ }^{[17-19]}$. This model produces reasonable results but it requires a good amount of 


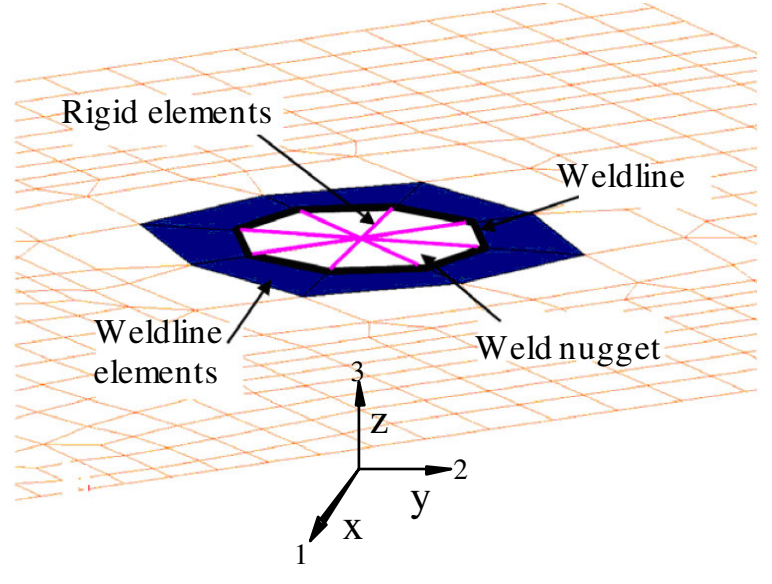

Fig. 4: FEM around spot weld nugget

effort for modeling and computational time. Therefore, the very detailed finite element modeling of spot welds is not feasible for 3000- 5000 spot welds in a typical automotive body structure ${ }^{[12]}$. Instead of the detailed modeling of the spot welds, a simple beam element represents a spot weld for fatigue calculation of the spot welds in a vehicle structure $\left.{ }^{[12,14,20}\right]$.

For the mesh insensitive structural stress calculation, the specimen for a spot welded joint is modeled with shell/plate, beam and rigid elements. The circular weld mark in each plate is modeled by triangular shell elements and rigid beams forming a spoke pattern as shown in Fig. 4. The rigid beam elements are connected from the center node to the peripheral nodal points of the circular weld marks in the both plates. Then the center nodes of the circular weld marks in both plates are connected with a beam element. Fig. 4 shows a finite element mesh around a circular weld mark. The geometry of the circular weld mark is required in the finite element model since the structural stress is calculated along the periphery of the weld. The normal direction of the shell elements (weldline elements) along the outside of the weldline is important for the calculation of the structural stress. Here, the weldline is defined as the periphery of the weld mark as shown in Fig. 4. A beam element represents the weld nugget to connect the top and bottom sheet steels. The length of the beam element is determined to be equal to one half of the total thickness for two sheets.

\section{FINITE ELEMENT ANALYSIS}

The nodal forces and moments in a global coordinate system at each mesh corner along the weld line (nugget periphery) with respect to the shaded

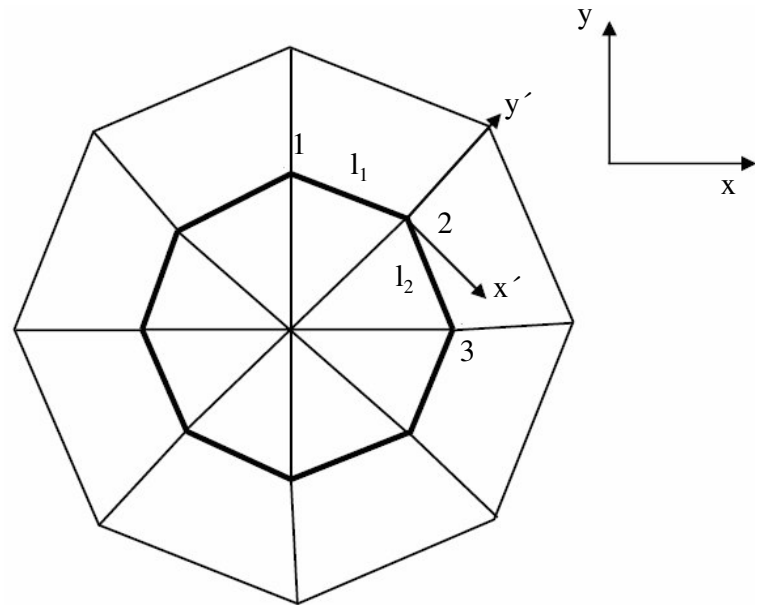

Fig. 5: Local coordinate system at a grid point

elements in Fig. 4 are directly obtained from a linear elastic finite element analysis. The forces and moments in the global coordinate system are then transferred into the local coordinate systems since the structural stresses are defined as those components normal to the weld line of the spot weld. Figure 5 shows a local coordinate system at a node used to convert the global forces and moments to local forces and moments on the weldline.

The nodal forces and moments in the local coordinate system are then converted to the distributed forces in terms of line forces and moments using the assumption that the work done by the nodal forces is equal to the work done by the distributed forces. The transfer equations for the line forces and moments are derived along the welding between to nodes on the weld periphery. The simultaneous equations for converting local forces to line forces are shown in Eq. 4:

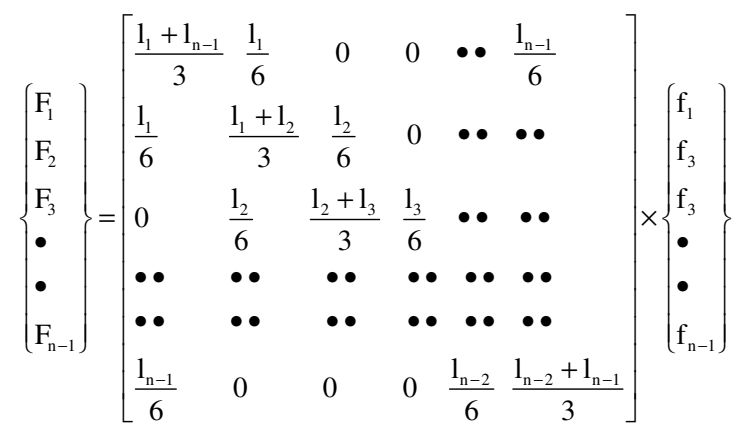

where, $\mathrm{f}_{1}, \mathrm{f}_{2}, \mathrm{f}_{3}, \ldots \mathrm{f}_{\mathrm{n}-1}$ are the line forces at nodal point $1,2,3, \ldots, \mathrm{n}-1$ and $\mathrm{F}_{1}, \mathrm{~F}_{2}, \mathrm{~F}_{3}, \ldots, \mathrm{F}_{\mathrm{n}-1}$ are the nodal forces in local coordinate systems at the nodal point 1 , $2,3, \ldots, \mathrm{n}-1$. The line forces at nodal point $\mathrm{n}$ is the 


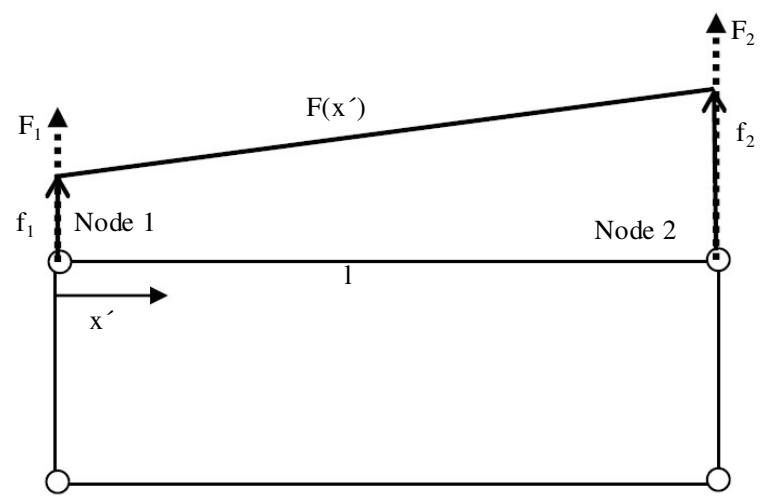

Fig. 6: Definition of the line forces at the nodal element

same as the line force at nodal point 1 since the weldline along the nugget periphery is closed. The line forces and nodal forces are presented for a single element case in Fig. 6. The line moments at the nodal points can be obtained from the nodal moments in the local coordinate systems suing simultaneous equations similar to Eq. 4.

Linear static stress is calculated suing the line forces and moments at each nodal point on the periphery of the nugget. The structural stress consists of a membrane stress component $\left(\sigma_{\mathrm{m}}\right)$ and a bending stress component $\left(\sigma_{\mathrm{b}}\right)$ at each nodal points as expressed in Eq. $5^{[15-16]}$ :

$$
\sigma=\sigma_{\mathrm{m}}+\sigma_{\mathrm{b}}=\frac{\mathrm{fy}^{\prime}}{\mathrm{t}}+\frac{6 \mathrm{~m}_{\mathrm{x}^{\prime}}}{\mathrm{t}^{2}}
$$

where, $\mathrm{t}$ represents sheet thickness, $\mathrm{fy}^{\prime}$ is the line force in the direction of $\mathrm{y}^{\prime}$ and $\mathrm{m}_{\mathrm{x}^{\prime}}$ is the line moment about $\mathrm{x}^{\prime}$ axis in a local coordinate system as shown in Fig. 5. The structural stress $(\sigma)$ was shown to be constant even though the size of the finite element mesh was changed $^{[15-16,21]}$.

The specimen geometry and dimensions with the finite element meshes are shown in Fig. 7. Eight nodal points are located along the weldline of the spot weld in the finite element models for tensile shear and coach peel specimens. The sheet thickness of the specimens was $0.2-1.2 \mathrm{~mm}$ and the diameter of the spot weld was considered $2.5 \mathrm{~mm}$ to $8.5 \mathrm{~mm}$ in the finite element models. One side of the specimen was constrained in all directions and the other side of the specimen was constrained in all directions except the direction of the loading that was applied at the center of the grip with RBE3 elements ${ }^{[22]}$. The RBE3 stands for rigid body element type 3 . This element distributes the loads on the reference node to a set of nodes connected to the

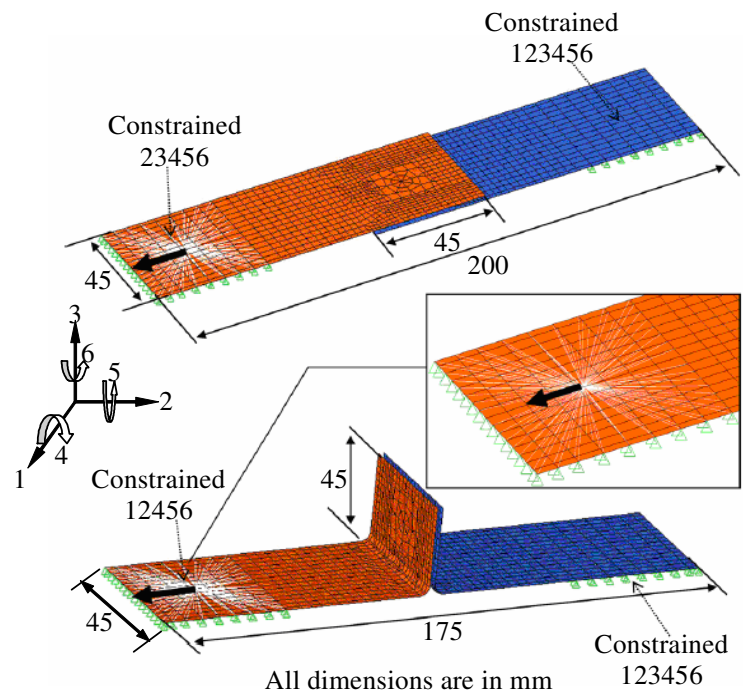

Fig. 7: Dimensions and FEM for tensile shear and coach peel specimens
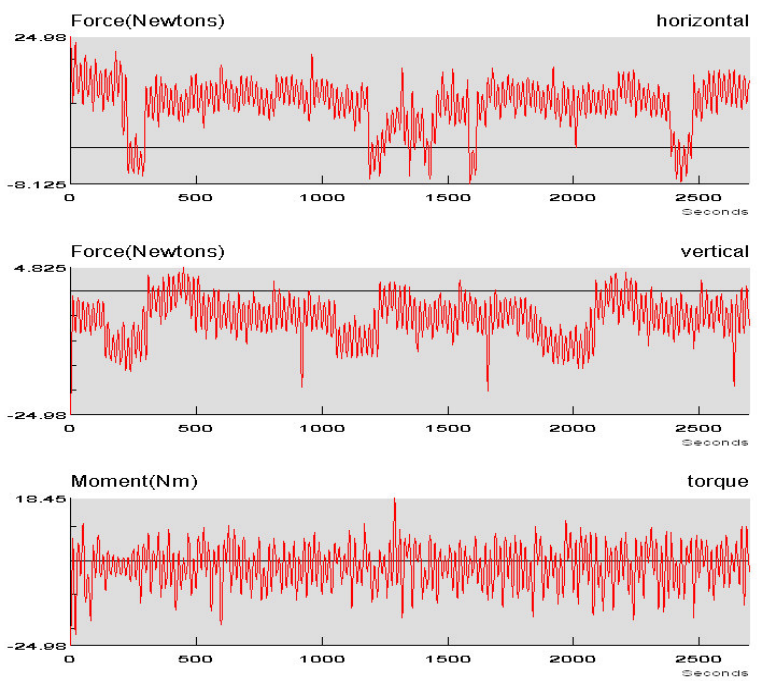

Fig. 8: Load-time histories

RBE3 element without adding extra stiffness in the model ${ }^{[23]}$. The sheet- 2 is loaded with $25 \mathrm{~N}$ loads in the $\mathrm{X}, \mathrm{Y}$ and $\mathrm{Z}$ directions while the legs of the sheet-1 are clamped at the edges. The load-time histories are shown in Fig. 8.

\section{MATERIALS PROPERTIES}

The data on material properties required for the numerical calculations were collected after extensive search through information of literatures and handbooks. Table 1 shows the mechanical and fatigue 
Am. J. Applied Sci., 6 (1): 137-142, 2009

Table 1: Mechanical and fatigue properties of the sheets and nugget

\begin{tabular}{lllll}
\hline Name of Properties & Sheet-1 & Sheet-2 & Nugget & Unit \\
\hline Modulus of elasticity & 205900 & 205900 & 205900 & $\mathrm{MPa}$ \\
Ultimate tensile strength & 500 & 500 & 500 & $\mathrm{MPa}$ \\
Poison's ratio & 0.3 & 0.3 & 0.3 & \\
$\begin{array}{l}\text { Density } \\
\text { Stress range intercept (SRI1) }\end{array}$ & 7850 & 7850 & 7850 & $\mathrm{Kg} \mathrm{m}^{-3}$ \\
$\begin{array}{l}\text { First fatigue strength } \\
\text { exponent (b })\end{array}$ & -0.1667 & -0.1667 & -0.1667 & \\
Fatigue transition point & $1 \times 10^{-6}$ & $1 \times 10^{-6}$ & $1 \times 10^{-6}$ & Cycles \\
Second fatigue strength & -0.0909 & -0.0909 & -0.0909 & \\
exponent (b $)$ & & & & \\
Mean stress sensitivity & 0.1 & 0.1 & 0.1 & \\
Standard error of Log (N) & 0.334 & 0.334 & 0.330 & \\
\hline & & & &
\end{tabular}

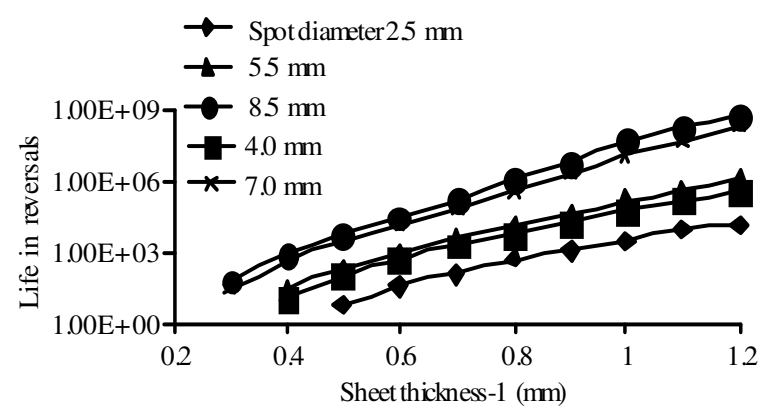

Fig. 9: Effect of spot diameter and sheet-1 thickness on the fatigue life

properties of the sheets and nugget in which the young's modulus, poison's ratio and density and so on.

\section{RESULTS AND DISCUSSION}

The aim of this study was to illuminate the effect of sheet thickness on the fatigue behavior of spot welds and in particular to investigate the use of fatigue life prediction approach. In this respect, the problem was a special one due to the geometry of the spot weld contains a stress singularity. The model clearly needs to be tested against more experimental data in a variety of situations, an exercise which is beyond the scope of this study.

Figures 9 and 10 show the effect of the sheet thickness and spot diameter on the fatigue life of the spot weld structure. Spot weld diameter of 2.5-8.5 mm and sheet thickness for 1 and 2 of $0.2 \mathrm{~mm}$ to $1.2 \mathrm{~mm}$ are considered in this study. It can be seen that from Fig. 9 and 10, the spot weld diameter and the thickness of the sheet metals are influences the fatigue life of the structure. It is observed that the fatigue life of the structure increases with the increases of the spot weld diameter and thickness of the sheet.

Figure 11 and 12 show the effects of the loads and confidence of survival on the fatigue life on the spot

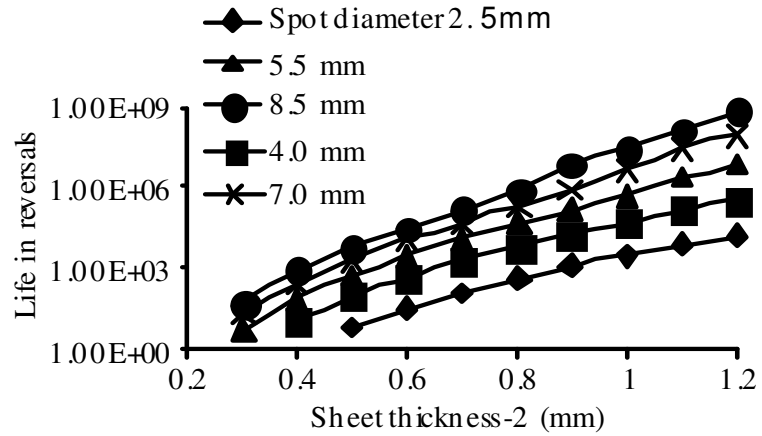

Fig. 10: Effect of spot diameter and sheet-2 thickness on the fatigue life

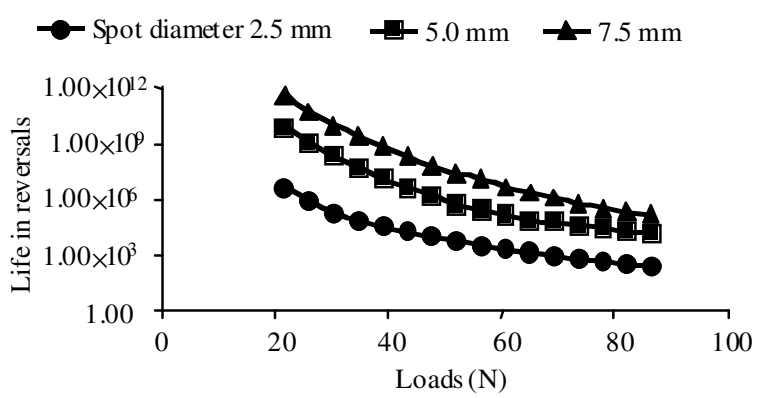

Fig. 11: Effects of the loads on the spot fatigue life

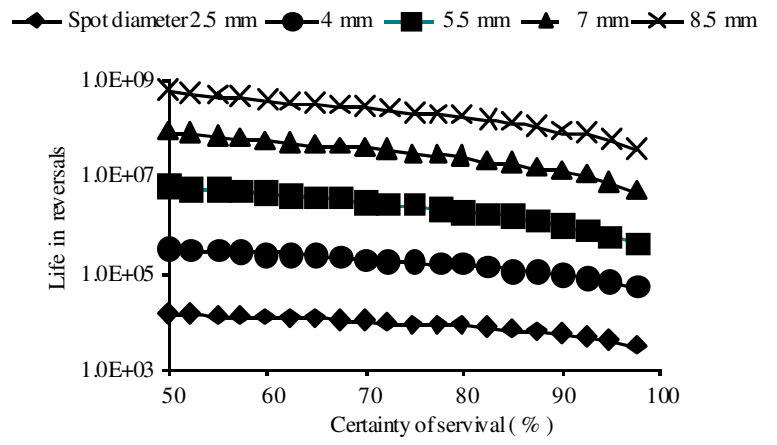

Fig. 12: Effect of the confidence of survival on the fatigue life

weld structure. From the obtained results, it can be seen from Fig. 11 that the fatigue life decreases linearly with the increases of loads, however, the increases of fatigue life with increases of spot weld diameter. The obtained results from Fig. 12, it is clearly seen that the fatigue life influences on the confidence of survival parameter which is based on the standard error of the S-N curves. The prediction of the fatigue life distribution with the range of probabilities of 50-97.5\% is shown in Fig. 12. 


\section{CONCLUSION}

A computational technique developed and has been applied to predict the fatigue life of spot welded structures in tensile loading. In this study, the effect of sheet and nugget diameter was investigated under variable amplitude loading. The behavior of diameter of spot weld and sheet thicknesses are very important parameters in stress distribution near spot welds. The acquired results seen that the spot diameter and thickness of the sheets are greatly influence the fatigue life of the spot welded structures. This application and related experiments will be the subject of further investigations. The effects of the loading and geometric configuration on the fatigue life of spot welded joints can be directly incorporated in the structural stress method.

\section{ACKNOWLEDGMENT}

The authors would like to express their thanks to the Universiti Malaysia Pahang for financial support under the project (No: RDU070347) and provides the laboratory facilities.

\section{REFERENCES}

1. Ewing, K.W., M. Cheresh, R. Thompson and P. Kukuchek, 1982. Static and impact strengths of spot welded HSLA and low carbon steel joints. SAE Technical Paper No. 820281.

2. Zhang, Y. and D. Toylor, 2000. Sheet thickness effect of spot welds based on crack propagation. Eng. Fracture Mech., 67: 55-63.

3. Pan, N. and S.D. Sheppard, 2003. Stress intensity factors in spot welds. Eng. Fracture Mech., 70: 671-684.

4. Lee, Y.L., T.J. Wehner, M.W. Lu, T.W. Morrissett and E. Pakalnins, 1998. Ultimate strength of resistance spot welds subjected to combined tension and shear. J. Test. Evaluat., 26: 213-219.

5. Wung, P.C., 2001. A force based failure criterion for spot weld analysis. J. Exp. Mech., 41: 107-113.

6. Wung, P., T. Walsh, A. Ourchane, W. Stewart and M. Jie, 2001. Failure of spot welds under in-plane static loading. J. Exp. Mech., 41: 100-106.

7. Wilson, R.B., Fine, T.E., 1981. Fatigue behavior of spot welded high strength steel joints. SAE Technical Paper No. 810354.

8. Davidson, J.A., 1983. A review of the fatigue properties of spot-welded sheet steels. SAE Technical Paper No. 830033.
9. Jung, W.W., P.K. Jang and S.S. Kang, 1996. Fatigue failure and reinforcing method of spot welded area at the stage of vehicle development. SAE Technical Paper No. 960553.

10. Kang, H., M.E. Barkey and Y.Lee, 2000. Evaluation of multiaxial spot weld fatigue parameters for proportional loading. Int. J. Fatigue, 22: 691-702.

11. Radaj, D. and S. Zhang, 1991. Stress intensity factors for spot welds between plates of unequal thickness. Eng. Fracture Mech., 39: 391-413.

12. Rupp, A., K. Srorzel and V. Grubisic, 1995. Computer aided dimensioning of spot welded automotive structures. SAE Technical Paper No. 950711.

13. Zhang, S., 2004. A simplified spot weld model for finite element analysis. SAE Technical Paper No. 2004-01-0818.

14. Kang, H.A., 2005. A fatigue damage parameter of spot welded joints under proportional loading. Int. J. Automot. Technol., 6: 285-291.

15. Dong, P., 2001. A robust structural stress procedure for characterizing fatigue behavior of welded joints. SAE Technical Paper. 2001-01-0086.

16. Dong, P., 2001. A structural stress definition and numerical implementation for fatigue analysis of welded joints. International Journal of Fatigue, 23(10): 865-876.

17. Lin, P.C., S.H. Lin andJ. Pan, 2006. Modeling of failure near spot welds in lap-shear specimens based on a plane stress rigid inclusion analysis. Eng. Fracture Mech., 73: 2229-2249.

18. Wang, D.A. and J.A. Pan, 2005. A computational study of local stress intensity factor solution for linked cracks near spot welds in lap-shear specimens. Int. J. Solids Struct., 42: 6277-98.

19. Lee, H. and J. Choi, 2005. Overload analysis and fatigue life prediction of spot welded specimens using an effective j-integral. Mech. Mater., 37: 19-32.

20. Sheppard, S.D., 1996. Further refinement of a methodology for fatigue life estimation in resistance spot weld connections. Adv. Fatigue Predict. Tech., 3: 265-282.

21. Dong, P. and J.K. Hong, 2002. CAE weld durability prediction: a robust single damage parameter approach. SAE Technical Paper No. 2002-01-0151.

22. MSC.NASTRAN, 2005. User's Manual. USA: MSC Software Inc.

23. MSC.NASTRAN, 2005. Linear Static Analysis User's Guide. USA: MSC Software Inc. 